\title{
1 Examination of geostatistical and machine-learning techniques as \\ 2 interpolators in anisotropic atmospheric environments
}

3 Jovan M. Tadić ${ }^{a, \#}$, Velibor Ilić ${ }^{b}$ and Sebastien Biraud

4

$5 \quad{ }^{a}$ Department of Global Ecology, Carnegie Institution for Science, Stanford, CA 94305, USA

$6 \quad{ }^{\mathrm{b}}$ RT-RK Institute for Computer Based Systems, 21000 Novi Sad, Serbia

$7 \quad{ }^{\mathrm{c}}$ Lawrence Berkeley National Laboratory, Berkeley, CA 94720, USA

8 " corresponding author

9 e-mail adreesses: jtadic@ stanford.edu (J. Tadić), ilicv@EUnet.rs (V. Ilić), SCBiraud@ lbl.gov (S. Biraud).

Abstract: Selecting which interpolation method to use significantly affects the results of atmospheric studies. The goal of this study is to examine the performance of several interpolation techniques under typical atmospheric conditions. Several types of kriging and artificial neural networks used as spatial interpolators are here compared and evaluated against ordinary kriging, using real airborne $\mathrm{CO}_{2}$ mixing-ratio data and synthetic data. The real data were measured (on December 26, 2012) between Billings and Lamont, near Oklahoma City, Oklahoma, within and above the planetary boundary layer (PBL). Predictions were made all along the flight trajectory within a total volume of $5000 \mathrm{~km}^{3}$ of atmospheric air $(27 \times 33 \times 5.6 \mathrm{~km})$. We evaluated (a) universal kriging, (b) ensemble neural networks, (c) universal kriging with ensemble neural network outputs used as covariates, and (d) ensemble neural networks with ordinary kriging of the residuals as interpolation tools. We found that in certain cases, when the weaknesses of ordinary kriging interpolation schemes (based on an omnidirectional isotropic variogram presumption) became apparent, more sophisticated interpolation methods were in order. In this study, preservation of the potentially nonlinear relationship between the trend and coordinates (by using neural kriging output as a covariate in a universal kriging scheme) was attempted, with varying degrees of success (it was best performer in 4 out of 8 cases). The study confirmed the necessity of selecting an interpolation approach that includes a combination of expert understanding and appropriate interpolation tools. The error analysis showed that uncertainty representations generated by the kriging methods are superior to neural networks, but that the actual error varies from case to case. 


\section{Introduction}

A standard interpolation technique in atmospheric sciences has not yet been established, mainly because of the complex properties of atmospheric fields, as well as the fact that this area of science is still in its initial stages. Because atmospheric data are commonly recorded at scattered or localized sampling locations, it is often necessary to spatially interpolate the data in order to: (a) organize the recording into a regular grid, (b) query the data for estimations at a particular location of interest, or (c) allow for integration of measured data or their derivatives over definite domains of area or space (i.e., calculation of fluxes based on a mass-balance approach-see Mays et al., 2009, Cambaliza et al., 2014). Interpolation accuracy can significantly affect results of atmospheric studies. For example, the major source of uncertainty typically reported in remote-sensing validation studies is the uncertainty resulting from the extrapolation of profiles above and below the sampled vertical fraction of the full atmospheric column (Tadic et al., 2014; Tanaka et al., 2012). In a recent study of the sources of uncertainty in urban outflow quantifications, based on a mass-balance approach (Cambaliza et al., 2014), the change in interpolation method resulted in a $12 \pm 14 \%$ change in calculated $\mathrm{CO}_{2}$ fluxes from Indianapolis, Indiana, but only two interpolation methods were intercompared: ordinary kriging, and a version of the local polynomial regression (LPR) method.

A detailed general review of spatial interpolation techniques commonly used in environmental studies can be found elsewhere (Li and Heap, 2008; Li and Heap, 2011). It has been shown that uncertainty within estimates depends on many factors, among which data variation plays the most important role. Other important factors are sampling density (Stahl et al., 2006), sample spatial distribution (Collins and Bolstad, 1996), sample clustering (Laslet, 1994), quality of secondary information (Hengl, 2007), stratification (Brus et al., 1996), and grid size and resolution (Hengl, 2007), with possible interactions among these factors (Zimmerman et al., 1999).

Interpolations of atmospheric data face a few specific challenges. The presumption of planetary boundary layer (PBL) stationarity, required for common kriging-based interpolations, is inherently invalid, both in terms of the stationarity in time and second-order spatial stationarity (often resulting from present stratification, as well as directional and zonal anisotropy). The effects of the mismatch between interpolation assumptions and reality add to other sources of uncertainty in such studies. For example, in a recent study of urban outflow, the authors used kriging and a mass-balance approach to determine emission fluxes (Mays et al., 2009). The 
reported uncertainties in flux estimates were found to be $\sim 80 \%$ for $\mathrm{CO}_{2}$ and $\sim 71 \%$ for $\mathrm{CH}_{4}$. However, in addition to uncertainties in wind speed and background mixing-ratio determinations reported to be primary sources of uncertainty, there were a few nonquantified sources: (a) the impact of local fluctuations in mixing-ratios during the flight time (average hourly $\mathrm{CO}_{2}$ variations within PBL can exceed 1 ppm, Arshinov et al., 2009),

(b) uncertainties in interpolations stemming from the imperfections in the applied theoretical variogram model (Li and Heap, 2014), and (c) the correlated nature of errors at each estimation location, which did not allow for a direct estimate of uncertainty (Neuman and Jacobson, 1984). Thus, realistic estimates of uncertainty very likely exceeded the reported values, partially resulting from the interpolation-related causes. The role accurate interpolations play in understanding atmospheric structure and phenomena is clearly demonstrated in several recent studies of: PBL thermal structure (Laiti et al., 2013a; Laiti et al., 2013b), uncertainty sources in airborne measurement (Cambaliza et al., 2014), urban outflow (Mays et al., 2009), and air pollution patterns (Pope and $\mathrm{Wu}, 2014)$.

Further advancements in the selection or development of a proper interpolation tool would be beneficial for future atmospheric studies, in particular airborne flux measurements/calculations from localized sources. The present study has two goals: (1) to examine four interpolation methods within the context of atmospheric measurements and the urban outflow quantification problem, and (2) to attempt to methodologically improve interpolation techniques based on universal kriging by including machine-learning-based interpolations as covariates. We intercompared: (a) universal kriging (UK), (b) ensemble neural kriging (ENK, also known as predictions as covariates (UKNK), and (d) ensemble neural kriging with ordinary kriged residuals (NKOK). Ordinary kriging technique was used as a baseline. Examined methods were applied to an irregularly sampled set of atmospheric $\mathrm{CO}_{2}$ mixing-ratio data, measured along a rosette-shaped flight trajectory near Oklahoma City, Oklahoma, US, and two simple models. We assessed the improvements in universal kriging prediction accuracy by including ENK outputs as covariates. This idea stems from the assumption that a complex relationship between the trend of the data and coordinates should be captured by ENK predictions, which, if true, would enable the user to avoid predefining polynomial functional forms of coordinates to be used as covariates (see Section 2.4.4).

94 In interpolation studies, the most commonly used error measures included: mean error (ME), 
In Li and Heap, 2011, two new error measures were suggested: relative mean absolute error (RMAE) and relative root mean square error (RRMSE), both of which are insensitive to changes in units/scales. We adopted the suggestion by Li and Heap (2011) and expressed errors as RMAE and RRMSE in the present study.

\section{Material and Methods}

\subsection{Measurements}

The $\mathrm{CO}_{2}$ mixing-ratio data used in this study were measured on Dec 26, 2012, between Billings and Lamont near Oklahoma City, within and above the PBL. The US Department of Energy (DOE) supports a large testbed $(\sim 300 \times 300 \mathrm{~km})$ for measurements and modeling of atmospheric and climatic variables in the US Southern Great Plains (Ackerman et al., 2004). The heart of the SGP site is the heavily instrumented central facility (CF) located at $36^{\circ} 37^{\prime} \mathrm{N}, 97^{\circ} 30^{\prime} \mathrm{W}, 314 \mathrm{~m}$ (AMSL), near the town of Lamont, Oklahoma. In 2002, airborne observations over the CF started as part of a joint effort between the ARM program, the Earth System Research Laboratory (ESRL) of the US National Oceanic and Atmospheric Administration (NOAA), and the LBNL ARM Carbon project (Biraud et al., 2013). The focus of this last project (Biraud et al., 2013) was to collect aerosol and trace-gas vertical profiles onboard a small, manned aircraft (Cessna 172).

The typical flight pattern consisted of a series of 12 level legs at standard altitudes, ranging from $460 \mathrm{~m}$ to 5,500 $\mathrm{m}$ (AMSL) centered over the $60 \mathrm{~m} \mathrm{CF}$ tower (Figure 1b). Each leg was flown at constant altitude and lasted 5 minutes (below 1,800 m) or 10 minutes (above 1,800 m). We measured $\mathrm{CO}_{2}$ continuously (AOS, Inc. analyzer), and collected flasks for the NOAA-ESRL global flask network, during weekly flights and intensive campaigns.

\subsection{Modeling}

Two simple 3D models were created to test the capabilities of examined interpolation methods:

(1) The first model was created by assuming that Billings, Garber, Lamont and Nardin, OK, present local sources of $\mathrm{CO}_{2}$, and that the mixing-ratio of $\mathrm{CO}_{2}$ decreases exponentially in all directions. The stipulated $\mathrm{CO}_{2}$ mixing-ratio deviations from the background equal the sum of the perturbations caused by each of the polluting urban centers: 
125

126

127

128

129

130

131

132

133

134

135

136

137

138

139

140

141

142

143

144

145

146

147

148

149

where $P_{\mathrm{CO}_{2}}$ equals the true mixing ratio on the prediction grid, $a_{i}$ represents unique coefficients proportional to the number of citizens $(8,15,9.3,5.1$ for Billings, Garber, Lamont and Nardin, OK, respectively) and $d_{i}$ represents distances in meters from the prediction point to polluting urban centers. In the text below, a model created in this way is called "4-spheres model" (4S).

(b) The second model was created by assuming stratification of the air mass above the examined area and an exponential decrease of the mixing ratio in a vertical direction only:

$$
P_{\mathrm{CO}_{2}}=395+10 * \exp ^{-h / 10000}
$$

where $h$ represents the altitude (in meters) of the analyzed point. A model created in this way is called 'FLAT' in the text below.

The existence of known values on the grids allowed for a direct assessment of interpolation accuracy.

\subsection{Theory/Calculation}

\subsubsection{Variogram analysis}

Variogram analysis is a tool for quantifying spatial variability as a function of the separation distance between observations (Gringarten and Deutsch, 2001). A detailed analysis of the overall and directional variograms in $3 \mathrm{D}$ space was conducted to understand the spatial structure of the sampled data. Raw, experimental, and theoretical variograms were created for the entire dataset, and separately for the horizontal and vertical plane/axes. A raw variogram is calculated based on the subsampled observations, using:

$$
\gamma(h)=\frac{1}{2}\left[y\left(x_{i}\right)-y\left(x_{j}\right)\right]^{2}
$$

where $\gamma$ is the raw variogram value for a given pair of observations $y\left(x_{i}\right)$ and $y\left(x_{j}\right)$, and $h$ is the Euclidean distance between the locations $\left(x_{i}\right.$ and $\left.x_{j}\right)$ of these observations. Experimental variograms, obtained through binning and averaging raw variograms into a predefined number of bins (in this case 30), were fitted to a parametric function, the theoretical variogram, using 
150

151

152

153

154

155

156

157

158

159

160

161

162

163

164

165

166

167

168

169

170

171

172

173

174

175

176

177

nonlinear least squares. Directional variograms were created following the same procedure, but based only on pairs of points located within a predefined angle in horizontal or vertical directions (see Section 3.1).

\subsection{Interpolation techniques applied}

Kriging is most frequently used for spatial interpolations (Myers, 1991), while artificial neural networks generally have a much broader application. Application of artificial neural networks (ANNs) as spatial interpolators/predictors is often referred to as "neural kriging" (NK) because of the similarities between the two techniques (Rizzo et al., 1994). Kriging techniques have been classified as exact spatial interpolators, because they return the observed value as the interpolated value for known sample point locations; whereas ANNs, being approximate interpolators, do not (Merwin et al., 2002). In atmospheric applications, the impact of the approximate nature of predictions is unclear, because the inherent time dependence of the turbulence itself (Bernard and Wallace, 2002) implies that even two accurate consecutive collocated samplings within a “stationary" PBL would not give identical sampled values.

Kriging in this study was done in a Euclidean coordinate system, with GPS instruments recording data in Lat/Long/Alt format based on the WGS84 spheroid earth model (The Earth Model, 2014). Before kriging, the coordinates were converted into a Universal Transverse Mercator (UTM) coordinate system, to allow for computation of distances and angles using Euclidean geometry (Li and Heap. 2008).

\subsubsection{Universal kriging (UK)}

Universal kriging is the kriging technique used for data with a significant spatial trend. The inclusion of spatial explanatory variables accounts for the possible nonstationarity of the random field (Chiles and Delfiner, 2012). It is generally accepted that inclusion of secondary variables improves the accuracy of the predictions (Hengl, 2007). In our case, the cumulative plot (Figure 1a) points to height and height squared as possibly useful covariates, since the data above PBL seem to depend exclusively on vertical distance. Typically, a polynomial representation of the trend of the form:

$$
\mu(s)=\beta_{0}+\sum_{j=1}^{k} \beta_{j} s_{1}^{n_{j}} s_{2}^{m_{j}}
$$


178

179

180

181

182

183

184

185

186

187

188

189

190

191

192

193

194

195

196

197

198

199

200

201

202

203

204

205

206

207

is used, where $\beta$ represents coefficients (parameters), $s_{1}$ and $s_{2}$ are spatial coordinates of the observed phenomenon, and $n_{j}$ and $m_{j}$ are non-negative integer values. In practice, degrees $n_{j}$ and $\mathrm{m}_{\mathrm{j}}$ do not exceed two (Chiles and Delfiner, 2012). Spatial trends in phenomena that vary smoothly over space tend to be well approximated locally by such polynomial functions. They may involve many spatially nonlinear terms while still being linear in parameters.

\subsection{2 (Ensemble) Neural kriging (NK)}

ANNs have been proposed as an alternative method for spatial interpolation, given their ability to recognize patterns in data (Öztopal, 2006; Carvalho et al., 2007). The ANN approach obviates the need to specify a particular variogram (covariance) model (Rigol et al., 2001), makes no assumptions regarding stationarity, can handle nonlinear relationships (Openshaw and Openshaw, 1997), and can provide multiple realizations of the estimated field (Rizzo et al., 1994). In general, ensemble averaging often improves predictive accuracy (Marmion et al., 2009). Such a technique has been applied within various disciplines, such as ecology (Araújo, 2007), climatology (Raftery et al., 2005) and hydrology (Goswami et al., 2007). Thus, in this study, an ensemble of 25 ANNS was used in interpolations.

The results of our measurements contained 4554 sampled points in the following format: Latitude, Longitude, Altitude, $\mathrm{CO}_{2}$ mixing-ratio. Back-propagation ANNs had the following configuration: eight nodes at input, nine nodes at middle, and one node at the output layer. Input for the ANNs represented an array of eight values, which contained coordinates (longitude, latitude, and altitude), $\mathrm{CO}_{2}$ mixing-ratio for one of the reference points (see below), distance between current point and reference point, and relative values (longitude, latitude, and altitude) between current point (Point[X]) and reference points (RefPoint[Y]). Output values of the ANNs were the mixing-ratios of $\mathrm{CO}_{2}$. Reference points were extracted from measured data along the flight path (every $75^{\text {th }}$ point), resulting in 60 points extracted, and other measurements were used to generate the training set for the ANNs.

All values in the training set were first re-scaled into the 0-1 range. ANNs trainings and interpolations were done in ANN V2.5, a PC-based ANN software (Ilić, 2000). The inputs of the ANNs were calculated using the values of the estimation location and values of one of the reference points. When an ANN estimates the $\mathrm{CO}_{2}$ mixing-ratio at a certain point, it actually estimates mixing ratios at that point related to each of 60 reference points, the mean of which 
208

209

210

211

212

213

214

215

216

217

218

219

220

221

222

223

224

225

226

227

228

229

230

231

232

represents the final estimation. Generating a training set required determining eight input values and reference points. Those eight values were sent to the input nodes of all 25 ANNs in the ensemble. The final result was calculated as the average value of output results from the network ensemble.

\subsubsection{Universal kriging with explanatory data based on neural kriging (UKNK)}

The selection of polynomial functions of coordinates as covariates is often based on expert opinion and contains subjective elements. The outputs from ANNs contain the same information regarding the nonstationary properties of data. Thus, apart from using height and height squared as covariates, we tried using ensemble neural network predictions as covariates, creating a "hybrid" method that is more objective and less dependent on observer knowledge/intuition.

\subsubsection{Combined neural kriging-ordinary kriging (NKOK)}

Combined methods first use the approximate interpolation method (ENK), and then another interpolation technique (ordinary kriging), to predict the field of the expected residuals, using differences between observed and reproduced values at each sampled point. Interpolated values and residuals are then added together to produce the final predictions. In a recent study, such a combination of machine-learning method (random forest) and ordinary kriging of residuals proved to be superior over 22 other methods in predicting the mud content within a southwest Australian margin (Li et al., 2011).

\section{Results and Discussion}

The cumulative plot of $\mathrm{CO}_{2}$ mixing ratio versus altitude shown in Fig. 1a has two distinct features. First, it shows that above $\sim 1000 \mathrm{~m}$, mixing ratios basically do not depend on horizontal location; separate horizontal and vertical variograms also reflect this observed property (see Section 3.1). There is a large change in measured mixing-ratio values around $1000 \mathrm{~m}$, where the ratio suddenly changes by up to $\sim 6 \mathrm{ppm}$, which is a challenge for all smoothing interpolation methods, like kriging. 


\subsection{Variograms of the measured data}

234

235

236

237

238

239

240

241

242

243

244

245

246

247

Figure 2 shows a histogram and experimental variogram fitted with an exponential theoretical variogram model. Two different variograms were created to compare spatial variability in the data along horizontal and vertical directions separately, assuming those two directions to be principal axes of possible anisotropy (Figure 3).

The mixing-ratios were found to depend more on altitude and less on horizontal distance (Figure 3), and the variograms had different sills, implying a typical case of zonal anisotropy caused by stratification/layering in the PBL (Variogram, 2014). The observed spatial structure justified the use of kriging schemes that allowed for a variable mean, i.e., universal kriging.

A vertical variogram was created, taking into account points within a $\pm 15^{\circ}$ angle from the vertical axis, while a horizontal variogram used only a $\pm 5^{\circ}$ angle from the horizontal plane, due to more abundant sampled points in the horizontal direction (see Figure 1b). The higher sill in the vertical variogram points to the existence of an additional variance introduced in the vertical direction through stratification/layering. We believe that this observation might be typical of many experiments involving atmospheric sampling, and thus the kriging scheme must take into account the variable mean.

\subsection{Interpolation results based on measured data}

Universal kriging (UK). Figure 4 shows the results of all examined methods applied to measured data. In the absence of truth at estimation locations, the only way to interpret the data is through expert understanding of the encountered atmospheric situation.

Major spatial trends based on expert understanding of the cumulative plot shown in Figure 4 are preserved and captured by all applied methods. The structure of the data within the vertical grid clearly shows two separated zones, within and above the PBL (with the border line at $\sim 1000 \mathrm{~m}$ ). As with all kriging schemes, the interpolation uncertainty distribution map is dependent on the relative positions of the estimation grids and flight path (Figure 5).

Universal kriging with ENK covariates (UKNK). Using the ensemble neural network output as covariate, along with classical polynomial functions of height, is a new approach that we tested as part of this work. The results shown in Figure 4 (D-E) and Figure 6 indicate that predictions of this combined method seem not to resemble "averages" of the two methods, but rather have qualitatively new properties (see also Table 3, model 4S, grid $5600 \mathrm{~m}$ ) i.e., the range of predicted 

values on the horizontal grid at $2900 \mathrm{~m}$ differs from UK and ENK. The qualitative difference is manifested as a large circular zone of higher mixing ratios in Figure 4E, close to the center of the same grid. Similarly, the zone of lower mixing ratios (West) on the horizontal grid at $200 \mathrm{~m}$ seems to be spread more widely compared to ENK, where it originally came from, because in the UK scheme, the zone of higher mixing ratio was not present at all (Figure 4A).

The ability of ANNs to recognize more complex spatial trends automatically, without the need to pre-specify forms for the polynomial functions of coordinates, is valuable, especially taking into account the number of studies reporting good predictive properties from machine-learning techniques.

Ensemble neural kriging (ENK). ENK predictions are given in Figure 4 (G-I). The vertical trend component of the spatial mixing-ratio profiles is captured by the ENK technique. The distribution of outputs from ENK at multiple checked estimation locations followed Gaussian distribution, allowing calculation of the standard deviation and variance, directly comparable to universal kriging. In Figure 5, the uncertainties obtained in the described two ways are displayed. The relationship between ENK uncertainties and flight path is more complex than in the case of universal kriging. Figure 6 and Figure 5A-C show that 25 ANNs have better agreement at the upper portions of the sampled space, where horizontal variations in the mixing ratios are lower. At lower portions, where the spatial structure of the mixing ratio is more complex, the agreement between ENK predictions becomes more problematic. The apparent feature in Figure 5 is that contours of different variance zones in the horizontal grid at $200 \mathrm{~m}$ resemble the flight path. (A better agreement between ANNs is found closer to the flight path.) Calculated variances range from $\sim 0$ to $2.31 \mathrm{ppm}$ in the horizontal grid at $200 \mathrm{~m}$ height, 0.08 to $1.37 \mathrm{ppm}$ in the horizontal grid at $2900 \mathrm{~m}, 0.07$ to $1.06 \mathrm{ppm}$ in the horizontal grid at $5600 \mathrm{~m}$ height, and $\sim 0.06$ to $2.09 \mathrm{ppm}$ in the vertical grid (Figure 4). Overall, the agreement among networks is excellent, especially at higher altitudes.

Ensemble neural kriging with ordinary kriged residuals (NKOK). In this approach, the ENK is used for interpolating and reproducing the data set used for training purposes, and ordinary kriging is used to predict the field of the residuals over the entire prediction domain, using differences between observed and reproduced values at each observation location. Interpolated values and residuals are then added together to produce the final predictions. In a majority of the cases, the kriged residual values stayed below $0.1 \mathrm{ppm}$, which indicates that the NKOK method represents insignificant improvement compared to the ENK method. 


\subsubsection{Cross validation}

296

297

298

299

300

301

302

303

304

305

306

307

308

309

310

311

312

313

314

315

316

317

318

319

320

321

322

323

324

325

Five-segment cross-validation was used to evaluate the performances of all techniques except NKOK, whose performance was shown to be very similar to ENK. The sampled data were divided into five segments with an equal number of points. Each segment corresponded to one loop of the flight. This modification of the general K-fold cross-validation technique was used because we were especially interested in the capability of interpolation techniques to predict over longer spatial ranges. For the same reason, the common leave-one-out method was not used. Second, since segments corresponded to the sections of the flight path flown at different heights, the proposed analysis potentially leads to a better understanding of the vertical-signal variability impact on the performance of all examined methods.

The results in Table 1 show that ordinary kriging (OK) did not perform the best in any one of the segments. ENK was the best performer in four out of five segments, and UK performed best in one. Results also show the superiority of UK over OK in more complex environments, given that the difference between performances expressed as errors was shifting in favor of UK from the top to the bottom of the flight path. The error representation in ENK based on prediction scattering was not shown to be an adequate approach. The number of outliers not captured by one standard deviation of the ENK predictions was commonly 80-90\% of all data. Any randomly selected interpolation technique evaluated in this study would likely perform better than $\mathrm{OK}$ - a finding that has direct implications for future urban outflow (and other) studies.

\subsubsection{Comparative analysis of all methods}

Predicted values, together with the cumulative plot of the measured data (Fig 8 and Table 2), exhibit ranges slightly larger than ones expected upon visual examination of the cumulative plot alone, especially at $2900 \mathrm{~m}$.

The most apparent feature in Figure 4A and 4D is the sudden dip in the mixing ratios in the middle of the vertical grid, a dip caused by the rosette shape of the flight path. The effect does not resemble the expected mixing-ratio distribution, according to our understanding, and it seems that at this specific part of the estimation space, ENK performed best (Figure 4G) because it predicts a smooth, continual layer spreading all the way along the vertical grid. The UKNK method exhibited the same feature. One important feature of Figure 6 is that UKNK provides content different from UK and ENK, as the maximum value at $2900 \mathrm{~m}$ and minimum at $200 \mathrm{~m}$ exceed the extremes of the two other techniques. 
326

327

328

In the absence of truth and according to the cumulative plot in Figure 6, it seems that in the horizontal grid at $5600 \mathrm{~m}$, UKNK was the best performer, while at $2900 \mathrm{~m}$, ENK was the best performer, based on the lowest spread. The situation is more complicated at $200 \mathrm{~m}$; most likely, UK and UKNK did better than eNK at that altitude.

\subsection{Modeling}

Separate horizontal and vertical variograms for both models of the $3 \mathrm{D} \mathrm{CO}_{2}$ field, shown in Figure 7 (using only points within $\pm 5^{\circ}$ and $\pm 15^{\circ}$ from the horizontal plane and vertical axis), support our earlier conclusion. The FLAT model produced a variogram apparently similar to the one created using measured values (Figure 3). The 4S model variogram is shown in Figure 7a. Insignificant differences between horizontal and vertical variograms confirm general dissimilarity between $\mathrm{CO}_{2}$ field distribution in this model and the observed atmospheric situation. However, the model provided a framework for further testing of the methods.

The different behavior of the examined predictors at the far North-West part of the grid is interesting. The flight path shape allowed for only brief sampling of the zone with higher $\mathrm{CO}_{2}$ mixing-ratio. UK extrapolation curved projected values down towards the mean value (Figure 8D), while ENK considered the sampled point to be the beginning of a larger spatial trend and projected higher values beyond sampled points (Figure 8J). UKNK was in accord with UK representation of the observed situation and gave little weight to the ENK component of the "hybrid" prediction.

\subsection{Uncertainty/Variance}

In kriging schemes, estimated point variance is a natural byproduct of the kriging. To compare point variances coming from kriging schemes with uncertainty coming from ENK, we interpolated the results of $25 \mathrm{ANNs}$ at each estimation point with a Gaussian (normal) distribution curve.

From Figure 5, it follows that the spatial distribution of variances in the kriging schemes is related to the flight path shape, while in the ENK method, the relationship is less apparent. The consensus among networks is good, resulting in overall $~ 50 \%$ lower variances from ENK compared to UK kriging. However, lower estimation variance does not guarantee that the error representation by the model is accurate. 
Three error measures were used to evaluate the performance of all four examined interpolation methods. Two recently proposed new measures ( $\mathrm{Li}$ and Heap, 2011) remove the effect of unit/scale and are not sensitive to such changes. The first is relative mean absolute error (RMAE), given as:

$$
\operatorname{RMAE}=\frac{1}{n} \sum_{i=1}^{n}\left|\left(p_{i}-o_{i}\right) / o_{i}\right| \times 100
$$

and the second is relative root mean square error (RRMSE), as follows:

$$
\text { RRMSE }=\left[\frac{1}{n} \sum_{i=1}^{n}\left(\left|o_{i}-p_{i}\right| / o_{i}\right)^{2}\right]^{1 / 2} \times 100
$$

where $n$ is the number of observations or samples, $o$ is observed value, and $p$ is predicted or estimated values. The third error measure used, mean absolute error (MAE), gives estimates of the average error, but does not provide information about the relative size of the average difference, or the nature of differences comprising it:

$$
\operatorname{MAE}=\frac{1}{n} \sum_{i=1}^{n}\left|p_{i}-o_{i}\right|
$$

The RMAE results are shown in Table 3, and RRMSE and MAE are shown in Table A.1. The errors show the varying performances of the methods. Universal kriging using height and height squared as covariates showed the best properties in four out of eight cases. NKOK was the best method in two cases, and UKNK and ENK in one, each.

Our results support findings from earlier studies (Li and Heap, 2014) that OK and UK can yield similar interpolation, but quite different extrapolation estimates, as differences in horizontal grid at $2900 \mathrm{~m}$ in both the $4 \mathrm{~S}$ and Flat model are lower compared to two other grids, where values were predominantly extrapolated.

The benefits of using ENK outputs as covariates were not clearly demonstrated in the combined error analysis. There are some features that encourage further examination. First, errors produced by UK and UKNK were very close to each other in most cases. Second, even when ENK was a much worse performer than UK, UKNK produced errors much more similar to the UK scheme. However, when ENK was a better performer, the inclusion of ENK output as a covariate significantly improved UKNK compared to UK alone. UKNK also carries information that cannot be reduced to one of the "parent" techniques. UKNK performed better than UK in four out of eight cases. However, the methods show similar errors in cases when UK performed 
better, while in cases when UKNK performed better, the errors were significantly different in support of UKNK. This observation further encourages examination of UKNK and identification of the factors important in the actual error pattern.

As expected, NKOK compared to ENK performed better in seven out of eight cases, but was inferior compared to the UK or UKNK method (5 out of 8). The three cases in which NKOK did better than kriging, and when, overall, it was the best method, were within the "FLAT" model, a result that invites further examination of this method under different circumstances and studied random field shapes. The highest errors in the FLAT model were found in the horizontal grid at $200 \mathrm{~m}$, where all four methods struggled to extrapolate an exponentially increasing mixing ratio. A systematic bias in this case was demonstrated by the fact that ME and MAE had identical values but different signs in all four methods, which implied systematic underestimation.

We explored the large differences between point variances calculated by ENK and UK, by counting the percentage of points within and outside the boundaries defined by calculated uncertainties. The analysis showed that, in the $4 \mathrm{~S}$ model, $14.4 \%$ of all point values were found to be within uncertainty bounds predicted by ENK. In the UK approach the percentage was found to be $33.8 \%$, and in UKNK $33.4 \%$. In the FLAT model, only $12.3 \%$ of all point values were found within uncertainty bounds predicted by ENK, while in the UK, the percentage was 97.7\%, and in the UKNK, 96.3\%. The figures for NKOK are not shown, because the statistics for NKOK and ENK were very similar. Uncertainty estimates in ENK based on standard deviation of the ensemble members were not found to be reliable.

\section{Conclusions}

In this study, several interpolation approaches toward atmospheric mixing-ratio data were examined. The necessity for including ad hoc expert understanding of the observed phenomena, and prior checks for the present anisotropy, was clear.

The inclusion of a nonlinear relationship between trend and coordinates captured by ENK into a universal kriging scheme (as covariates) resulted in predictions significantly different from both UK and ENK. The approach showed some promising properties, in that it did better than universal kriging alone in four out of eight examined model cases. However, evidence of benefits was inconclusive, and probably requires more sophisticated models. The error representations in kriging schemes were shown to be satisfactory in most cases, while error statistics of ENK proved to be inadequate. 
414 The study shows that the applicability of the method cannot be evaluated per se, but only within 415 a framework precisely defined by random field distribution and spatial relationship between 416 sampling and prediction grid geometries. This conclusion challenges and questions the real value 417 of the review studies comparing interpolation methods applied to different variables under 418 different circumstances.

419 Acknowledgement. This work was supported by the National Aeronautics and Space 420 Administration (NASA) through grant no. NNX08AJ92G, and the National Science Foundation 421 (NSF) through grant no. 1342076. The experimental data were based upon work supported by 422 the U.S. Department of Energy, Office of Science, Office of Biological and Environmental 423 Research, Atmospheric System Research Program, under Award Number DE-AC02424 05CH11231. We thank Anna M. Michalak for input on the study design. The authors would also 425 like to thank Max Loewenstein (NASA Ames Research Center) for the discussions and helpful 426 suggestions.

\section{References}

429

430

431

432

433

434

435
Ackerman, T.P., Genio, A.D.D., Ellingson, R.G., Ferrare, R.A., Klein, S.A., McFarquhar, G.M., Lamb, P.J., Long, C.N., Verlinde, J., 2004. Atmospheric radiation measurement program science plan: current status and future direcitons of the ARM science program, US Department of Energy, Office of Biological and Environmental Research, Washington, DC.

Araújo, M.B., New, M., 2007. Ensemble forecasting of species distributions. Trends Ecol. Evol. $22(1), 42-47$.

Arshinov, M., Belan, B., Davydov, D., Inouye, G., Krasnov, O., Maksyutov, S., Machida, T., Fofonov, A., Shimoyama, K., 2009. Spatial and temporal variability of $\mathrm{CO}_{2}$ and $\mathrm{CH}_{4}$ concentrations in the surface atmospheric layer over West Siberia. Atmospheric and Oceanic Optics, 22(1), 84-93, doi:10.1134/S1024856009010126.

Bernard, P.S., Wallace, J.M., 2002. Turbulent Flow: Analysis, Measurement and Prediction, Wiley.

Biraud, S.C., Torn, M.S., Smith, J.R., Sweeney, C., Riley, W.J., Tans, P. P., 2013. A Multi-Year Record of Airborne $\mathrm{CO}_{2}$ observations in the U.S. Southern Great Plains. Atmos. Meas. Tech., 6, 751-763. 
444

445

446

447 448

449

450

451

452

453

454

455

456

457

458

459

460

461

462

463

464

465

466

467

468

469

470

Brus, D.J., de Gruijter, J.J., Marsman, B.A., Visschers, B.A., Bregt, A.K., Breeuwsma, A., 1996. The performance of spatial interpolation methods and choropleth maps to estimate properties at points: a soil survey case study. Environmetrics 7, 1-16.

Cambaliza, M. O. L., Shepson, P. B., Caulton, D. R., Stirm, B., Samarov, D., Gurney, K. R., Turnbull, J., Davis, K. J., Possolo, A., Karion, A., Sweeney, C., Moser, B., Hendricks, A., Lauvaux, T., Mays, K., Whetstone, J., Huang, J., Razlivanov, I., Miles, N. L., and Richardson, S. J.: Assessment of uncertainties of an aircraft-based mass balance approach for quantifying urban greenhouse gas emissions, Atmos. Chem. Phys., 14, 9029-9050, doi:10.5194/acp-14-9029-2014, 2014.

Carvalho A.R., Carvalho J C., Shiguemori E.H. Da Silva J.D. S., Ramos F.M., 2007. Neural network based models for the retrieval of methane concentration vertical profiles from remote sensing data. Anais XIII Simpósio Brasileiro de Sensoriamento Remoto, Florianópolis, Brasil, INPE, p. 6437-6442.

Chiles, J.-P., Delfiner, P., 2012. Geostatistics, Second edition, Wiley.

Collins, F.C., Bolstad, P.V., 1996. A comparison of spatial interpolation techniques in temperature estimation. Proceedings, Third International Conference/Workshop on Integrating GIS and Environmental Modeling, Santa Fe, NM. National Center for Geographic Information and Analysis, Santa Barbara, Santa Barbara, CA.

Goswami, M., O’Connor, K.M., 2007. Real-time flow forecasting in the absence of quantitative precipitation forecasts: a multi-model approach. J. Hydrol 334, 125-140.

Gringarten, E., Deutsch, C.V., 2001. Teacher's aide: variogram interpretation and modeling. Mathematical Geology 33 (4), 507-534.

Hengl, T., 2007. A Practical Guide to Geostatistical Mapping of Environmental Variables. Office for Official Publication of the European Communities, Luxembourg, p. 143.

Ilić, V., 2000. Force learn algorithm - training neural networks with patterns which have highest errors., Seminar on Neural Network Applications in Electrical Engineering "NEUREL 2000", Belgrade, Sponsored by IEEE Signal Processing Society, 46-48. 
471 Laiti, L., Zardi, D., de Franceschi, M. and Rampanelli, G., 2013a. Residual kriging analysis of 472 airborne measurements: application to the mapping of atmospheric boundary-layer thermal 473 structures in a mountain valley. Atmosph. Sci. Lett., 14: 79-85. doi: 10.1002/asl2.420.

474 Laiti, L., Zardi, D., de Franceschi, M., and Rampanelli, G., 2013b. Atmospheric boundary layer 475 structures associated with the Ora del Garda wind in the Alps as revealed from airborne and 476 surface measurements. Atmospheric Research, v. 132-133, p. 473-489. doi: $477 \quad$ 10.1016/j.atmosres.2013.07.006.

478 Li, J., Heap, A., 2008. A Review of Spatial Interpolation Methods for Environmental Scientists 479 No. Record 2008/23. Geoscience Australia, Canberra.

480 Li, J., Heap, A., Potter, A., Daniell, J.J., 2011. Application of machine learning methods to 481 spatial interpolation of environmental variables. Environmental Modelling \& Software, Vol. 482 26(12), 1647-1659.

483

484

485 486 review. Environmental Modelling \& Software 53: 173-189. doi: 10.1016/j.envsoft.2013.12.008.

487 Mays, K.L., Shepson, P.B., Stirm, B.H., Karion, A., Sweeney, C., Gurney, K.R., 2009. Aircraft488 based measurements of the carbon footprint of Indianapolis, Environ. Sci. Technol. 43, 73164897823.

490 Merwin, D.A., Cromley, R.G., Civco, D.L., 2002. Artificial neural networks as a method of 491 spatial interpolation for digital elevation models. Cartogr. Geogr. Inf. Sci., 29(2), 99-110.

492 Myers, D.E., 1991. Interpolation and estimation with spatially located data. Chemom. Intell. Lab. 493 Syst., 11(3), 209-228.

494 Neuman, S. P. and Jacobson, E. A., 1984. Analysis of Nonintrinsic Spatial Variability by 495 Residual Kriging with Applications to Regional Groundwater Levels. Math. Geol., v. 16, n. 5, p. 496 499- 521.

497 Openshaw, S., Openshaw, C., 1997. Artificial intelligence in geography. Chichester, U.K.: 498 Wiley. 
499 Öztopal, A., 2006. Artificial neural network approach to spatial estimation of wind velocity data. 500 Energ. Convers. Manage. 47(4), 395-406.

501 Pope R. and $\mathrm{Wu}, \mathrm{J} ., 2013$. Characterizing air pollution patterns on multiple time scales in urban 502 areas: a landscape ecological approach. Urban Ecosystems, 1-20, doi 10.1007/s11252-014-03575030.

504 Raftery, A.E., Gneiting, T., Balabdaoui, F., Polakowski, M., 2005. Using Bayesian model 505 averaging to calibrate forecast ensembles. Mon. Weather Rev. 133, 1155-1174.

506 Rigol, J.P., Jarvis, C.H., Stuart, N., 2001. Artificial neural networks as a tool for spatial 507 interpolation. Int. J. Geogr. Inf. Sci. 15, 323-343.

508 Rizzo, D.M., Dougherty, D.E., 1994. Characterization of acquifer properties using artificial 509 neural networks: Neural kriging. Water Resour. Res. 30, 483-497.

510 Stahl, K., Moore, R.D., Floyer, J.A., Asplin, M.G., McKendry, I.G., 2006. Comparison of 511 approaches for spatial interpolation of daily air temperature in a large region with complex 512 topography and highly variable station density. Agr. Forest Meteorol. 139, 224-236.

513 Tanaka, T., Miyamoto, Y., Morino, I., Machida, T., Nagahama, T., Sawa, Y., Matsueda, H., 514 Wunch, D., Kawakami, S., and Uchino, O.: Aircraft measurements of carbon dioxide and 515 methane for the calibration of ground-based high-resolution Fourier Transform Spectrometers 516 and a comparison to GOSAT data measured over Tsukuba and Moshiri, Atmos. Meas. Tech., 5, 517 2003-2012, doi:10.5194/amt-5-2003-2012, 2012.

518 The Earth Model:

519 http://www.ipni.net/publication/ssmg.nsf/0/0BDF314BF75B9FC1852579E5007691F9/\$FILE/SS 520 MG-11.pdf (last accessed 08/05/2014).

521 Variogram: http://www.statios.com/Resources/04-variogram.pdf (last accessed 08/05/2014).

522 Zimmerman, D., Pavlik, C., Ruggles, A., Armstrong, M.P., 1999. An experimental comparison 523 of ordinary and universal kriging and inverse distance weighting. Math. Geol. 31, 375-390. 
Table 1. Error analysis in cross-validation using 4 different techniques (the lowest error in each segment is highlighted).

\begin{tabular}{|c|c|c|c|c|c|c|c|c|c|c|c|c|c|c|c|c|c|c|c|c|}
\hline & \multicolumn{5}{|c|}{ OK } & \multicolumn{5}{|c|}{ UK } & \multicolumn{5}{|c|}{ ENK } & \multicolumn{5}{|c|}{ UKNK } \\
\hline & $\stackrel{\amalg}{\Sigma}$ & $\underset{\Sigma}{\stackrel{u}{\Sigma}}$ & $\sum_{\propto}^{\amalg}$ & 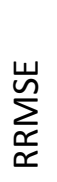 & 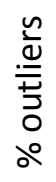 & $\stackrel{山}{\Sigma}$ & $\underset{\Sigma}{\longleftarrow}$ & $\sum_{\propto}^{\amalg}$ & 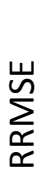 & 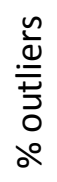 & $\stackrel{\amalg}{\Sigma}$ & 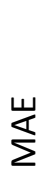 & $\sum_{\propto}^{\amalg}$ & 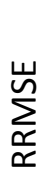 & 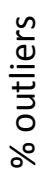 & $\stackrel{\amalg}{\Sigma}$ & $\underset{\Sigma}{\amalg}$ & $\sum_{\propto}^{\amalg}$ & 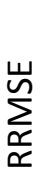 & 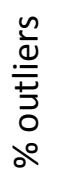 \\
\hline 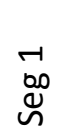 & $\begin{array}{l}\frac{9}{2} \\
\text { } \\
0\end{array}$ & 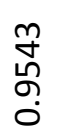 & $\begin{array}{l}0 \\
\stackrel{d}{d} \\
\stackrel{0}{0}\end{array}$ & 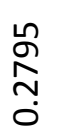 & $\stackrel{\circ}{\circ}$ & $\begin{array}{l}\overrightarrow{-} \\
\stackrel{-}{-}\end{array}$ & $\begin{array}{l}\text { ڤึ } \\
\text { ने } \\
\text { ने }\end{array}$ & $\begin{array}{l}\mathscr{\infty} \\
\stackrel{\infty}{+} \\
\dot{0}\end{array}$ & 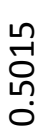 & $\begin{array}{l}\hat{\circ} \\
\dot{m}\end{array}$ & $\begin{array}{l}0 \\
\stackrel{0}{0} \\
0\end{array}$ & 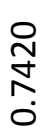 & $\begin{array}{l}\text { 文 } \\
\stackrel{+}{0}\end{array}$ & 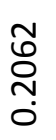 & $\begin{array}{l}\text { 우 } \\
\text { o̊ }\end{array}$ & $\begin{array}{l}\infty \\
\infty \\
+ \\
+\end{array}$ & 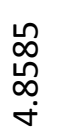 & $\underset{\sim}{\underset{r}{\sim}}$ & 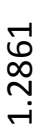 & $\begin{array}{l}\text { மூ } \\
\text { } \\
\text {. }\end{array}$ \\
\hline 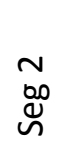 & $\begin{array}{l}\underset{\infty}{\rightarrow} \\
\underset{+}{+} \\
\dot{0}\end{array}$ & 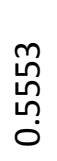 & $\stackrel{\vec{H}}{\stackrel{+}{\circ}}$ & $\frac{\stackrel{\infty}{\stackrel{n}{\sim}}}{\stackrel{-}{0}}$ & تِ & 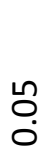 & $\begin{array}{l}\stackrel{\sigma}{\exists} \\
\text { ֶ̆ } \\
\stackrel{0}{0}\end{array}$ & $\begin{array}{l}\stackrel{+}{7} \\
\stackrel{-}{\circ}\end{array}$ & $\begin{array}{l}\stackrel{0}{\infty} \\
\stackrel{m}{\sim} \\
\stackrel{0}{0}\end{array}$ & $\begin{array}{l}\qquad \\
\varrho \\
0\end{array}$ & 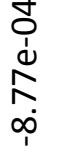 & $\begin{array}{l}\text { مे } \\
\text { ஸे } \\
\text { ஸे }\end{array}$ & $\stackrel{\stackrel{\infty}{\sim}}{\stackrel{0}{0}}$ & 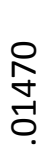 & $\begin{array}{l}\text { 굼 } \\
\text { م }\end{array}$ & $\begin{array}{l}\frac{0}{m} \\
m \\
0\end{array}$ & $\begin{array}{l}\text { 오 } \\
\text { ํㅜ } \\
\text { o }\end{array}$ & $\begin{array}{l}\underset{+}{+} \\
\stackrel{-}{0}\end{array}$ & 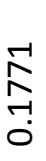 & बे \\
\hline $\begin{array}{l}m \\
\text { Do } \\
\mathbb{U} \\
\sim\end{array}$ & $\begin{array}{l}\underset{ }{ } \\
\stackrel{-}{-} \\
\end{array}$ & 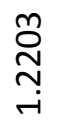 & $\begin{array}{l}\hat{\circ} \\
\text { nె } \\
0\end{array}$ & 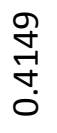 & $\begin{array}{l}\stackrel{n}{\sim} \\
\stackrel{\sim}{\sim}\end{array}$ & 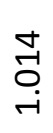 & $\begin{array}{l}\text { ㅇ } \\
\text { ○ } \\
\text { - }\end{array}$ & $\begin{array}{l}\text { } \\
\stackrel{\sim}{0} \\
0\end{array}$ & 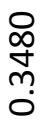 & $\begin{array}{l}\infty \\
\infty \\
\sigma \\
\sigma\end{array}$ & 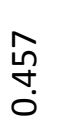 & $\begin{array}{l}\underset{\infty}{\infty} \\
\stackrel{\infty}{+} \\
\stackrel{0}{0}\end{array}$ & 굼 & $\begin{array}{l}\text { O্ } \\
\text { J } \\
\stackrel{-}{0}\end{array}$ & $\begin{array}{l}\text { مூ } \\
\text { ம் }\end{array}$ & $\begin{array}{l}\text { ڤె } \\
\infty \\
0\end{array}$ & 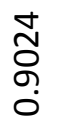 & $\begin{array}{l}\underset{N}{N} \\
\text { o }\end{array}$ & 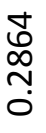 & $\begin{array}{l}\infty \\
\text { m } \\
\dot{n}\end{array}$ \\
\hline $\begin{array}{l}+ \\
\stackrel{\infty}{\infty} \\
\stackrel{\sim}{N}\end{array}$ & 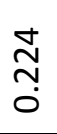 & 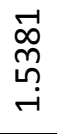 & $\begin{array}{l}\stackrel{\infty}{\infty} \\
\text { n̊ } \\
0\end{array}$ & $\begin{array}{l}\stackrel{0}{f} \\
\stackrel{y}{f} \\
\dot{0}\end{array}$ & $\begin{array}{l}\text { ָ̦ } \\
\text { iv }\end{array}$ & 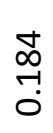 & $\begin{array}{l}\hat{\varphi} \\
\text { ه } \\
\stackrel{-}{-}\end{array}$ & $\underset{\substack{n \\
n}}{\stackrel{m}{n}}$ & 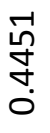 & $\begin{array}{l}\stackrel{\text { ஸn }}{\infty} \\
\stackrel{\infty}{\rightarrow}\end{array}$ & $\begin{array}{l}\stackrel{\bullet}{\stackrel{f}{f}} \\
\dot{0}\end{array}$ & 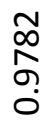 & $\begin{array}{l}\text { Na } \\
\text { ָ̊ }\end{array}$ & $\begin{array}{l}\text { Oे } \\
\stackrel{\sim}{m} \\
\stackrel{0}{0}\end{array}$ & $\begin{array}{l}\circ \\
\text { 궁 } \\
\infty\end{array}$ & $\begin{array}{l}\text { ભి } \\
\text { ọ } \\
\text { ọ }\end{array}$ & 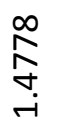 & $\begin{array}{l}\stackrel{P}{n} \\
\text { m. } \\
0\end{array}$ & 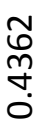 & $\begin{array}{l}\text { ○ } \\
\stackrel{\infty}{\sim}\end{array}$ \\
\hline 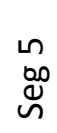 & $\begin{array}{l}\underset{\sim}{\sim} \\
\underset{\sim}{\sim}\end{array}$ & $\begin{array}{l}\underset{\sim}{\sim} \\
\overrightarrow{6} \\
\stackrel{\sim}{N}\end{array}$ & $\begin{array}{l}\text { 유 } \\
\text { } \\
0\end{array}$ & 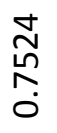 & $\begin{array}{l}\text { ळ } \\
\text { هं }\end{array}$ & $\begin{array}{l}\stackrel{n}{\rightarrow} \\
\underset{\sim}{\sim}\end{array}$ & $\begin{array}{l}\text { \& } \\
\text { ठ } \\
\stackrel{+}{-}\end{array}$ & $\begin{array}{l}\text { ळి } \\
\text { ஸ் }\end{array}$ & 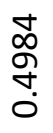 & $\begin{array}{l}\emptyset \\
\infty \\
\infty \\
0\end{array}$ & $\begin{array}{l}\text { જ̆ } \\
\text { ه̣ }\end{array}$ & 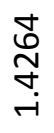 & 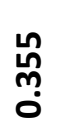 & $\begin{array}{l}\tilde{U} \\
\mathscr{0} \\
\stackrel{0}{0} \\
\text {. }\end{array}$ & $\begin{array}{l}\text { ○े } \\
\text { o }\end{array}$ & 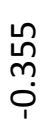 & 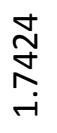 & 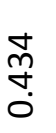 & $\begin{array}{l}\text { Oे } \\
\text { ஸे } \\
\text { ஸे }\end{array}$ & 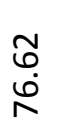 \\
\hline
\end{tabular}


Table 2. Max and min values of ENK, UK and UK with ENK covariate interpolation techniques. The ranges (max-min) at each horizontal grid were smallest using ENK and largest using UK method.

\begin{tabular}{|l|c|c|c|c|c|c|c|c|c|}
\hline & \multicolumn{3}{|c|}{ Ensemble ANNs (ppm) } & \multicolumn{3}{c|}{ UK (ppm) } & \multicolumn{3}{c|}{ UK with ANN covariate (ppm) } \\
\cline { 2 - 10 } & $\min$ & $\max$ & range & $\min$ & $\max$ & range & min & max & range \\
\hline $\begin{array}{l}\text { Horizontal } \\
\text { grid 200m }\end{array}$ & 399.39 & 403.32 & 3.93 & 397.95 & 404.96 & 7.01 & 397.74 & 403.68 & 5.94 \\
\hline $\begin{array}{l}\text { Horizontal } \\
\text { grid 2900m }\end{array}$ & 395.47 & 398.90 & 3.43 & 395.15 & 399.52 & 4.37 & 396.29 & 400.39 & 4.1 \\
\hline $\begin{array}{l}\text { Horizontal } \\
\text { grid 5600m }\end{array}$ & 396.29 & 397.78 & 1.49 & 395.16 & 397.00 & 1.84 & 395.60 & 397.22 & 1.62 \\
\hline
\end{tabular}

Table 3. Comparison of errors expressed as RMAE for two models in all four grids (the highest error in each estimation grid is highlighted).

\begin{tabular}{|c|c|c|c|c|c|c|c|c|c|c|}
\hline & \multicolumn{4}{|c|}{ Model 1 (4S) } & \multicolumn{5}{c|}{ Model 2 (FLAT) } \\
\cline { 2 - 11 } & OK & UK & ENK & UKNK & NKOK & OK & UK & ENK & UKNK & NKOK \\
\hline $\begin{array}{c}\text { Horizontal } \\
\text { grid 200m }\end{array}$ & 0.0786 & $\mathbf{0 . 0 7 7 2}$ & 0.1628 & 0.0858 & 0.1530 & 1.2286 & $\mathbf{0 . 3 1 4 4}$ & 0.4922 & 0.3974 & 0.4908 \\
\hline $\begin{array}{c}\text { Horizontal } \\
\text { grid 2900m }\end{array}$ & $\mathbf{0 . 0 6 6 0}$ & 0.0661 & 0.1622 & 0.0685 & 0.1535 & 0.3527 & 0.1249 & 0.0060 & 0.0586 & $\mathbf{0 . 0 0 5 3}$ \\
\hline $\begin{array}{c}\text { Horizontal } \\
\text { grid 5600m }\end{array}$ & 0.0798 & 0.0679 & 0.2449 & $\mathbf{0 . 0 6 5 6}$ & 0.2413 & 0.3487 & 0.0562 & $\mathbf{0 . 0 0 9 3}$ & 0.0245 & 0.0099 \\
\hline $\begin{array}{c}\text { Vertical } \\
\text { grid }\end{array}$ & 0.0182 & $\mathbf{0 . 0 1 2 4}$ & 0.0357 & 0.0125 & 0.0266 & 0.1994 & 0.0947 & 0.0314 & 0.0474 & $\mathbf{0 . 0 3 0 7}$ \\
\hline
\end{tabular}




\section{Appendix}

Table A.1

\begin{tabular}{|c|c|c|c|c|c|c|c|c|c|c|c|}
\hline & & \multicolumn{5}{|c|}{ Model 1 (4S) } & \multicolumn{5}{|c|}{ Model 2 (FLAT) } \\
\hline & & ํㅣ & $\breve{b}$ & $\underset{\text { Z }}{z}$ & $\begin{array}{l}\text { 岁 } \\
\text { b }\end{array}$ & $\begin{array}{l}\text { v) } \\
\text { bै } \\
\text { 乙 }\end{array}$ & oै & $\breve{b}$ & $\underset{z}{z}$ & $\begin{array}{l}\text { 岁 } \\
\text { b }\end{array}$ & $\begin{array}{l}y \\
0 \\
\frac{y}{z}\end{array}$ \\
\hline \multirow{3}{*}{ 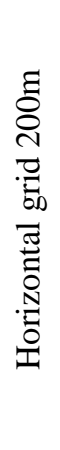 } & $\stackrel{1}{\Sigma}$ & $\begin{array}{l}\text { fo } \\
\frac{1}{i}\end{array}$ & $\begin{array}{l}n \\
0 \\
0\end{array}$ & $\underset{\stackrel{+}{+}}{\stackrel{\sim}{0}}$ & $\begin{array}{l}n \\
\tilde{o} \\
0\end{array}$ & $\frac{n}{0}$ & $\begin{array}{l}\hat{n} \\
\hat{n} \\
\dot{+}\end{array}$ & $\begin{array}{l}\infty \\
\stackrel{\infty}{\rightarrow} \\
\rightarrow\end{array}$ & 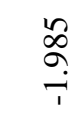 & 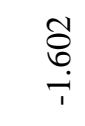 & $\frac{\mathfrak{\sigma}}{\mathfrak{T}}$ \\
\hline & $\sum_{\Sigma}^{L}$ & $\frac{a}{\tilde{a}}$ & $\frac{m}{n}$ & $\begin{array}{l}\overline{0} \\
\stackrel{0}{0}\end{array}$ & 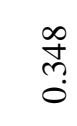 & $\begin{array}{l}\vec{\sigma} \\
0\end{array}$ & $\begin{array}{l}\hat{n} \\
\hat{\sigma} \\
\dot{\gamma}\end{array}$ & $\begin{array}{l}\infty \\
\stackrel{\infty}{\sim} \\
\end{array}$ & $\begin{array}{l}\mathscr{2} \\
\stackrel{-}{-}\end{array}$ & $\begin{array}{l}\text { ô } \\
\text { ọ } \\
-\end{array}$ & 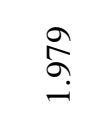 \\
\hline & $\sum_{\alpha}^{\infty}$ & $\begin{array}{l}\tilde{b} \\
\stackrel{n}{0} \\
\stackrel{0}{0}\end{array}$ & $\begin{array}{l}\dot{t} \\
\stackrel{n}{0}\end{array}$ & 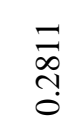 & $\frac{\stackrel{g}{0}}{0}$ & $\frac{\tilde{n}}{\stackrel{n}{n}}$ & 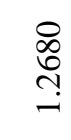 & $\begin{array}{l}\stackrel{+}{\sim} \\
\stackrel{\overbrace{}}{0}\end{array}$ & $\begin{array}{l}\text { तু } \\
\stackrel{+}{+}\end{array}$ & $\begin{array}{l}\text { a } \\
\text { oे } \\
\text { ஸे }\end{array}$ & $\begin{array}{l}\stackrel{8}{\circ} \\
\stackrel{a}{+} \\
\dot{0}\end{array}$ \\
\hline \multirow{3}{*}{ 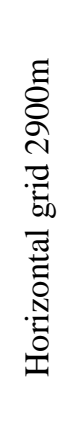 } & $\stackrel{\Perp N}{\Sigma}$ & $\begin{array}{l}\bar{\infty} \\
\varnothing \\
\delta \\
\dot{\varphi}\end{array}$ & $\begin{array}{l}\hat{S} \\
0 \\
0 \\
1\end{array}$ & $\frac{\vec{m}}{\overrightarrow{0}}$ & $\begin{array}{l}\stackrel{2}{\hat{0}} \\
0 \\
0\end{array}$ & $\stackrel{\infty}{\stackrel{\infty}{0}}$ & $\begin{array}{l}n \\
\infty \\
\infty \\
n \\
n\end{array}$ & 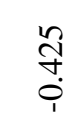 & $\begin{array}{l}\overrightarrow{\widehat{o}} \\
\stackrel{0}{0}\end{array}$ & $\begin{array}{l}\text { సે } \\
\text { } \\
\stackrel{1}{1}\end{array}$ & $\begin{array}{l}0 \\
0 \\
0 \\
0\end{array}$ \\
\hline & $\sum_{\Sigma}^{\infty}$ & $\begin{array}{l}\tilde{\sigma} \\
\stackrel{1}{0}\end{array}$ & 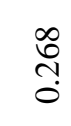 & $\begin{array}{l}\hat{n} \\
0 \\
0\end{array}$ & $\stackrel{\hat{N}}{0}$ & $\begin{array}{l}\tilde{N} \\
0 \\
0\end{array}$ & 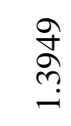 & $\begin{array}{l}\text { I } \\
\stackrel{+}{+} \\
\stackrel{0}{0}\end{array}$ & $\begin{array}{l}\stackrel{d}{d} \\
\stackrel{0}{0}\end{array}$ & $\begin{array}{l}\text { त̂ } \\
\text { ஸे }\end{array}$ & $\begin{array}{l}\vec{\delta} \\
0 \\
0\end{array}$ \\
\hline & $\sum_{\frac{\alpha}{\alpha}}^{N}$ & $\frac{\hat{o}}{\stackrel{d}{0}}$ & $\frac{\tilde{I}}{\stackrel{\Im}{0}}$ & $\begin{array}{l}\stackrel{2}{\infty} \\
\stackrel{\infty}{0} \\
\stackrel{1}{0}\end{array}$ & $\frac{\stackrel{g}{J}}{\stackrel{0}{0}}$ & 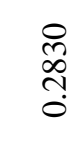 & $\begin{array}{l}\vec{N} \\
\stackrel{+}{+} \\
\dot{0}\end{array}$ & $\frac{\stackrel{?}{J}}{\stackrel{f}{0}}$ & $\begin{array}{l}\stackrel{2}{0} \\
8 \\
\stackrel{8}{0}\end{array}$ & $\begin{array}{l}0 \\
\infty \\
\varnothing \\
\dot{0}\end{array}$ & $\begin{array}{l}0 \\
\stackrel{8}{8} \\
0 \\
\dot{0}\end{array}$ \\
\hline \multirow{3}{*}{ 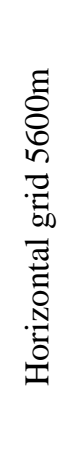 } & $\stackrel{N}{\Sigma}$ & $\stackrel{\stackrel{尺}{+}}{\stackrel{0}{0}}$ & $\overline{8}$ & 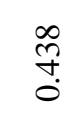 & $\begin{array}{l}\infty \\
0 \\
0 \\
0 \\
0\end{array}$ & 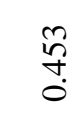 & 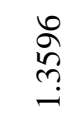 & $\frac{\text { Iे }}{3}$ & $\stackrel{\hat{\sigma}}{0}$ & $\begin{array}{l}\text { I } \\
0 \\
0 \\
0\end{array}$ & હે \\
\hline & $\underset{\Sigma}{\frac{1}{4}}$ & 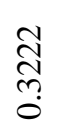 & 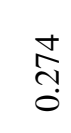 & $\begin{array}{l}2 \\
0 \\
0 \\
0\end{array}$ & 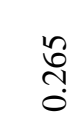 & $\frac{n}{a}$ & $\underset{n}{\stackrel{n}{n}}$ & 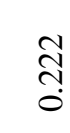 & 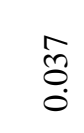 & ồ & હે \\
\hline & 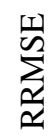 & 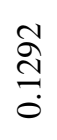 & $\frac{m}{\stackrel{n}{0}}$ & $\begin{array}{l}\text { 尺 } \\
\text { n } \\
\text { ñ }\end{array}$ & $\frac{\infty}{\infty}$ & $\begin{array}{l}\infty \\
\text { o } \\
\text { ?n } \\
0\end{array}$ & 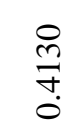 & 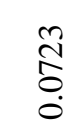 & $\begin{array}{l}\mathscr{\delta} \\
\stackrel{8}{0}\end{array}$ & $\begin{array}{l}\stackrel{8}{0} \\
\text { Oे } \\
\dot{0}\end{array}$ & $\begin{array}{l}8 \\
\stackrel{0}{0} \\
\stackrel{0}{\circ}\end{array}$ \\
\hline \multirow{2}{*}{ 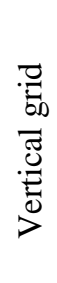 } & $\stackrel{ \pm}{\Sigma}$ & 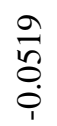 & $\begin{array}{l}2 \\
0 \\
0 \\
0\end{array}$ & $\begin{array}{l}n \\
0 \\
0 \\
0\end{array}$ & $\begin{array}{l}\widehat{\hat{O}} \\
\stackrel{0}{0}\end{array}$ & ָे & $\begin{array}{l}\frac{J}{\sigma} \\
\dot{0} \\
\dot{0}\end{array}$ & $\begin{array}{l}\infty \\
\stackrel{\infty}{0}\end{array}$ & $\begin{array}{l}0 \\
\infty \\
0 \\
0\end{array}$ & $\begin{array}{l} \pm \\
\stackrel{0}{0} \\
\dot{0}\end{array}$ & $\begin{array}{l}n \\
0 \\
0 \\
0 \\
0\end{array}$ \\
\hline & $\underset{\Sigma}{\mathbb{2}}$ & $\begin{array}{l}\hat{0} \\
\stackrel{0}{0} \\
0\end{array}$ & $\begin{array}{l}0 \\
\qquad \\
0 \\
0\end{array}$ & $\frac{n}{8}$ & $\begin{array}{l}0 \\
0 \\
0 \\
0\end{array}$ & $\begin{array}{l}\stackrel{\infty}{0} \\
\stackrel{0}{0}\end{array}$ & $\begin{array}{l}\frac{a}{2} \\
\frac{0}{0}\end{array}$ & $\underset{\hat{n}}{\hat{n}}$ & $\frac{0}{\mathbb{N}}$ & $\frac{\infty}{0}$ & $\frac{\tilde{I}}{0}$ \\
\hline
\end{tabular}




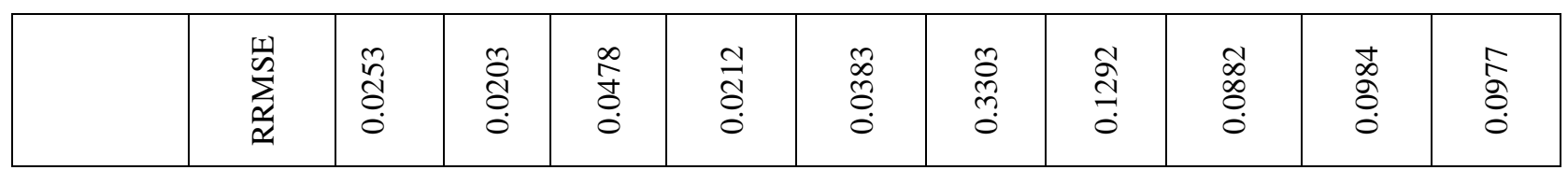



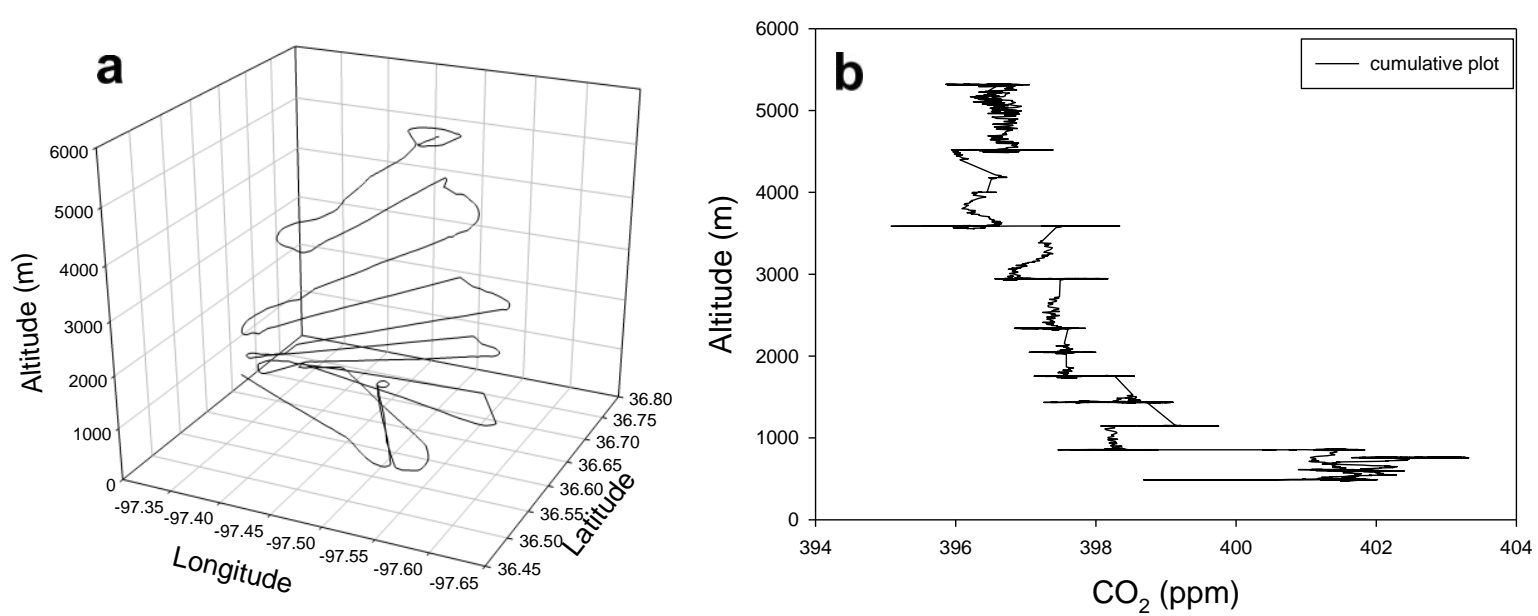

Figure 1. (a) 3D flight trajectory, (b) Cumulative plot of the mixing ratio of $\mathrm{CO}_{2}$ as a function of altitude for the whole flight. The plot shows that, above PBL, mixing ratios depend only on altitude; horizontal coordinates seem to be irrelevant.
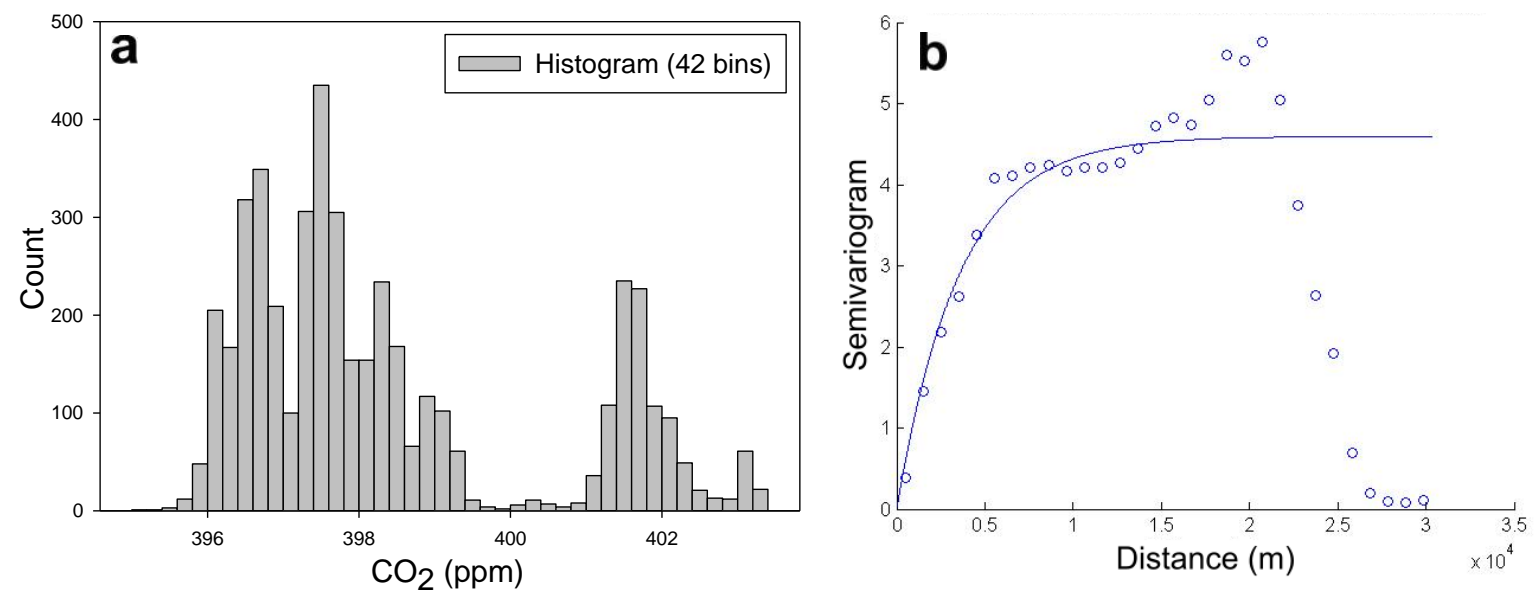

Figure 2. (a) Histogram (shows two distinctive groups of points, each one with the distribution approaching normal one. However, overall distribution is not Gaussian. (b) Experimental and theoretical variograms. Exponential covariance model was used, fitted into first one third of the experimental variogram and subsequently used in two interpolation techniques (UK, UKNK). 


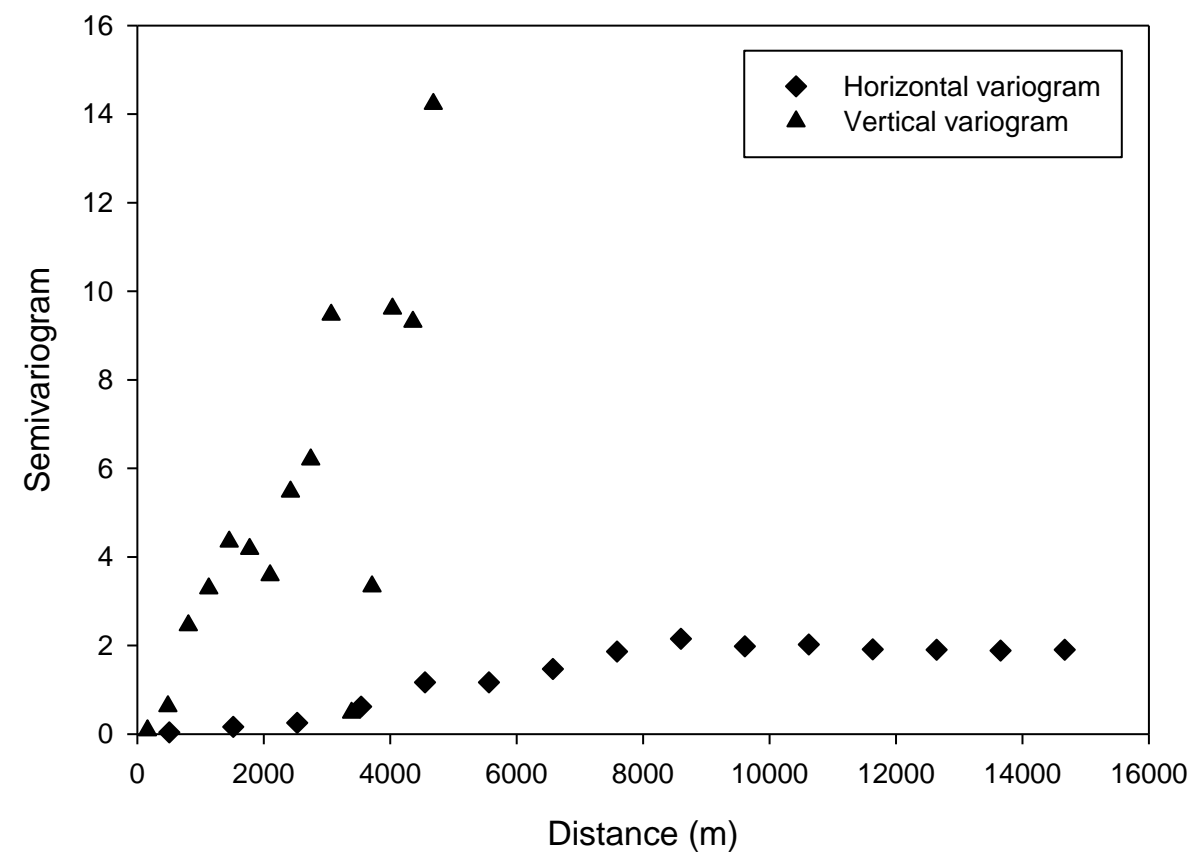

Figure 3. Separate vertical and horizontal experimental (empirical) variograms exhibit not only different ranges but also different sills, indicating a case of zonal anisotropy.
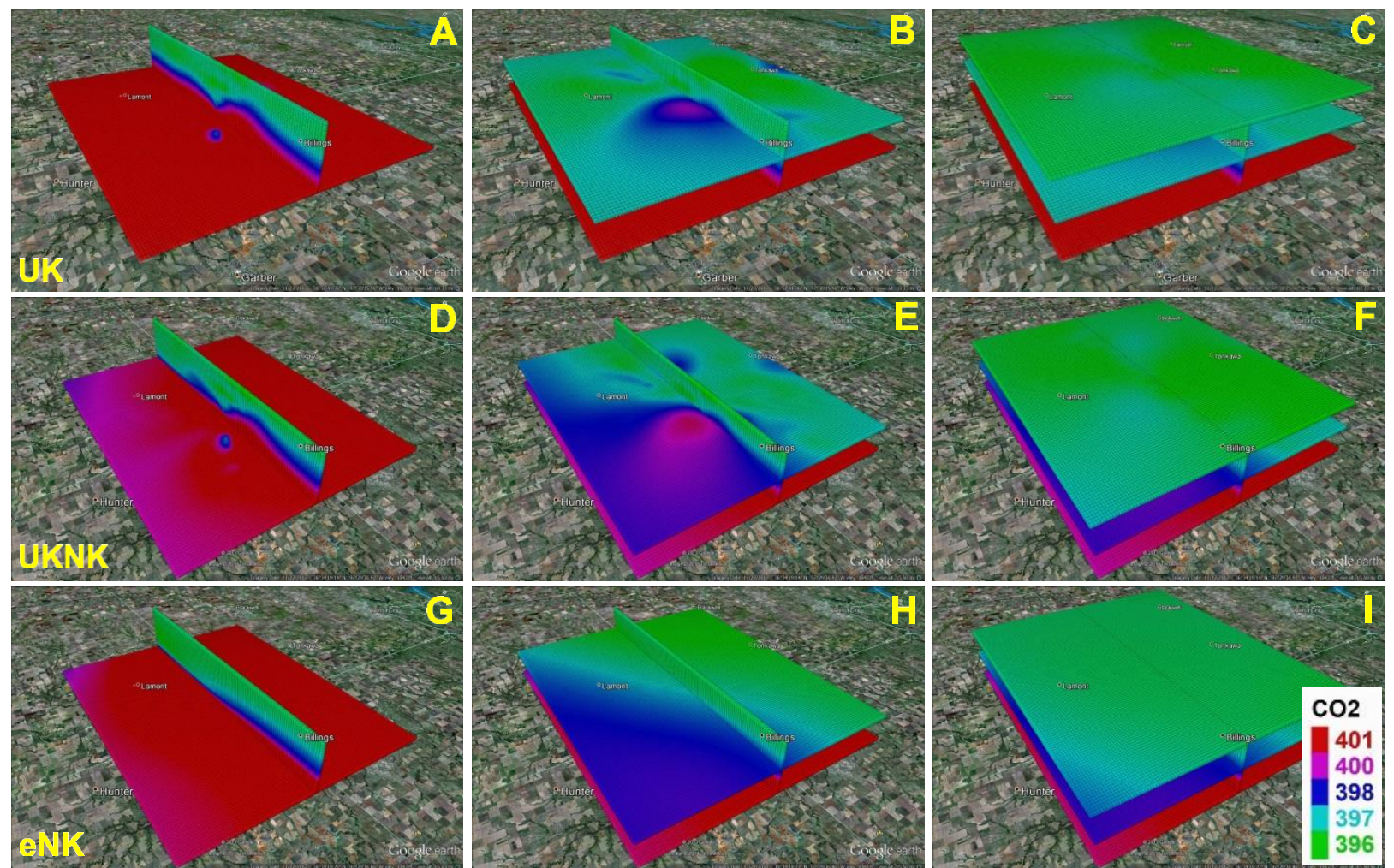

Figure 4. (A-C) Universal kriging (UK) predictions using altitude and altitude squared as covariates on four numerical grids (three horizontal and one vertical). (D-F) Universal kriging predictions using ensemble neural network output together with altitude and altitude squared as covariates (UKNK). (G-I) Ensemble neural network predictions (ENK). Ensemble neural network predictions with ordinary kriged covariates (NKOK) are not shown 
due to their similarities to ENK. All four applied methods are capable of distinguishing vertical trends (zonal structure).
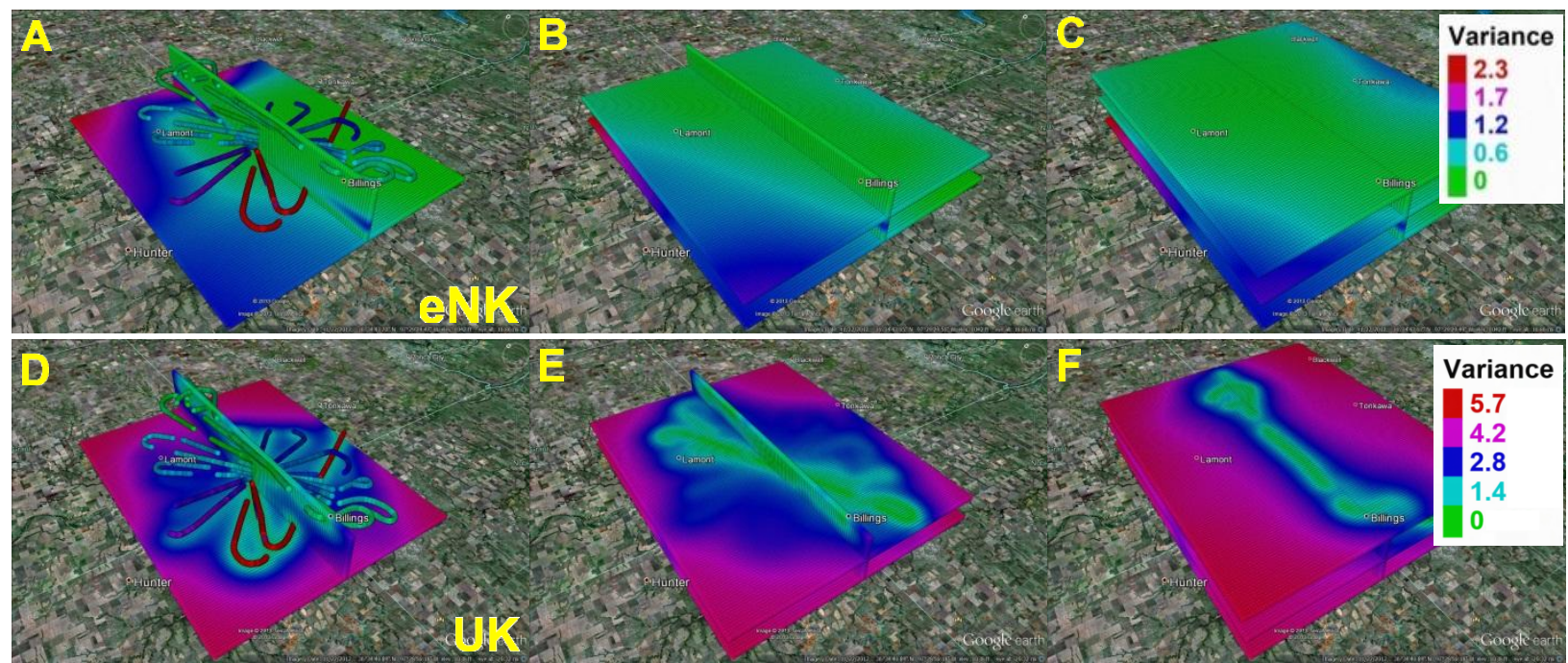

Figure 5. Maps of uncertainty given as variances of the ensemble neural networks (eNK) (A-C), and universal kriging (UK) (D-F) estimates in all four projection grids (color legend pertains only to uncertainty, while flight path color is given in different color scale (legend not shown)). UK and especially UKNK gave the highest variances.

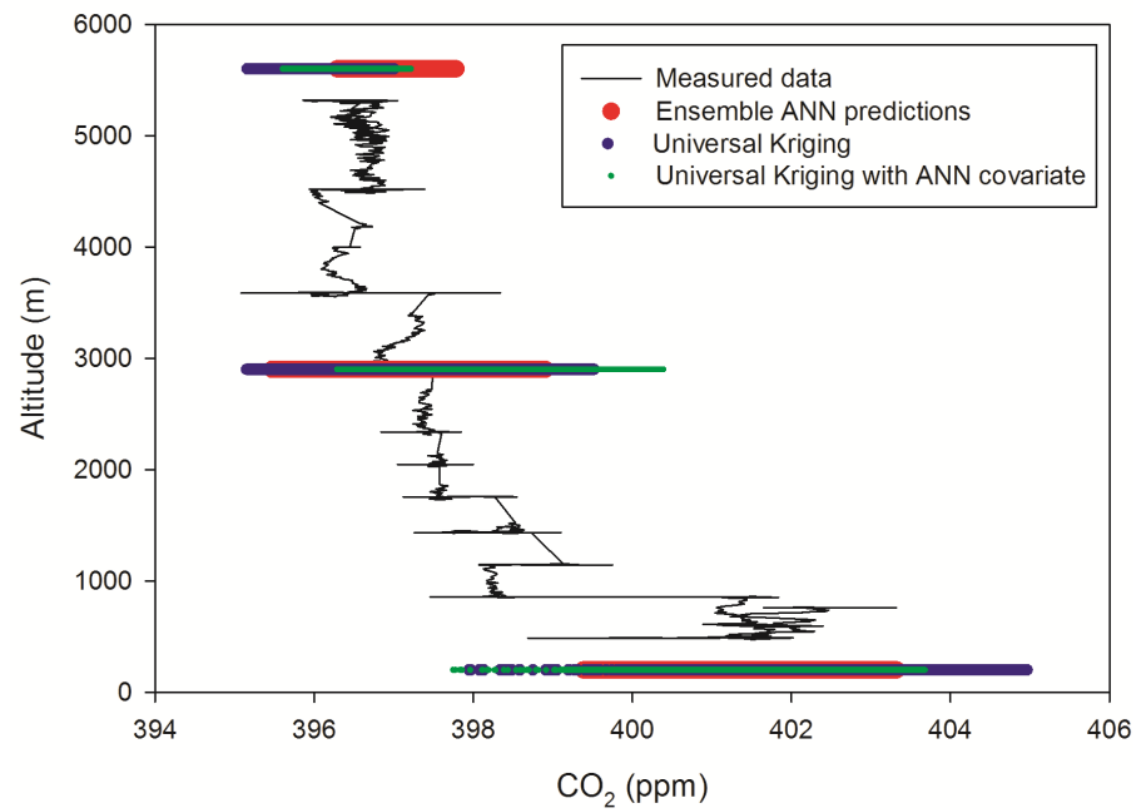

Figure 6. Cumulative plot of the measured data along with predictions based on ensemble ANN, universal kriging and universal kriging using both polynomial height functions and ensemble ANN output as covariates. NKOK results are not shown because they are only slightly different from ENK alone. 

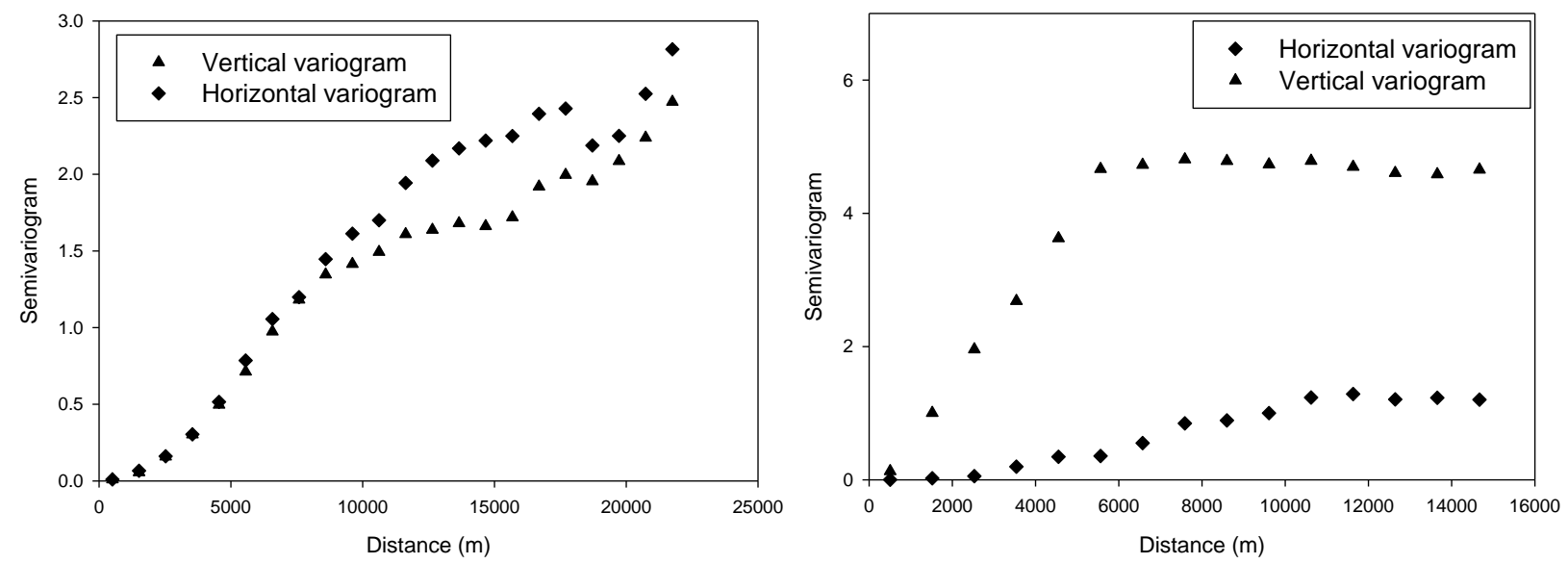

Figure 7. Separated horizontal and vertical variograms for A) Model 1 (4S) and B) Model 2 (FLAT).
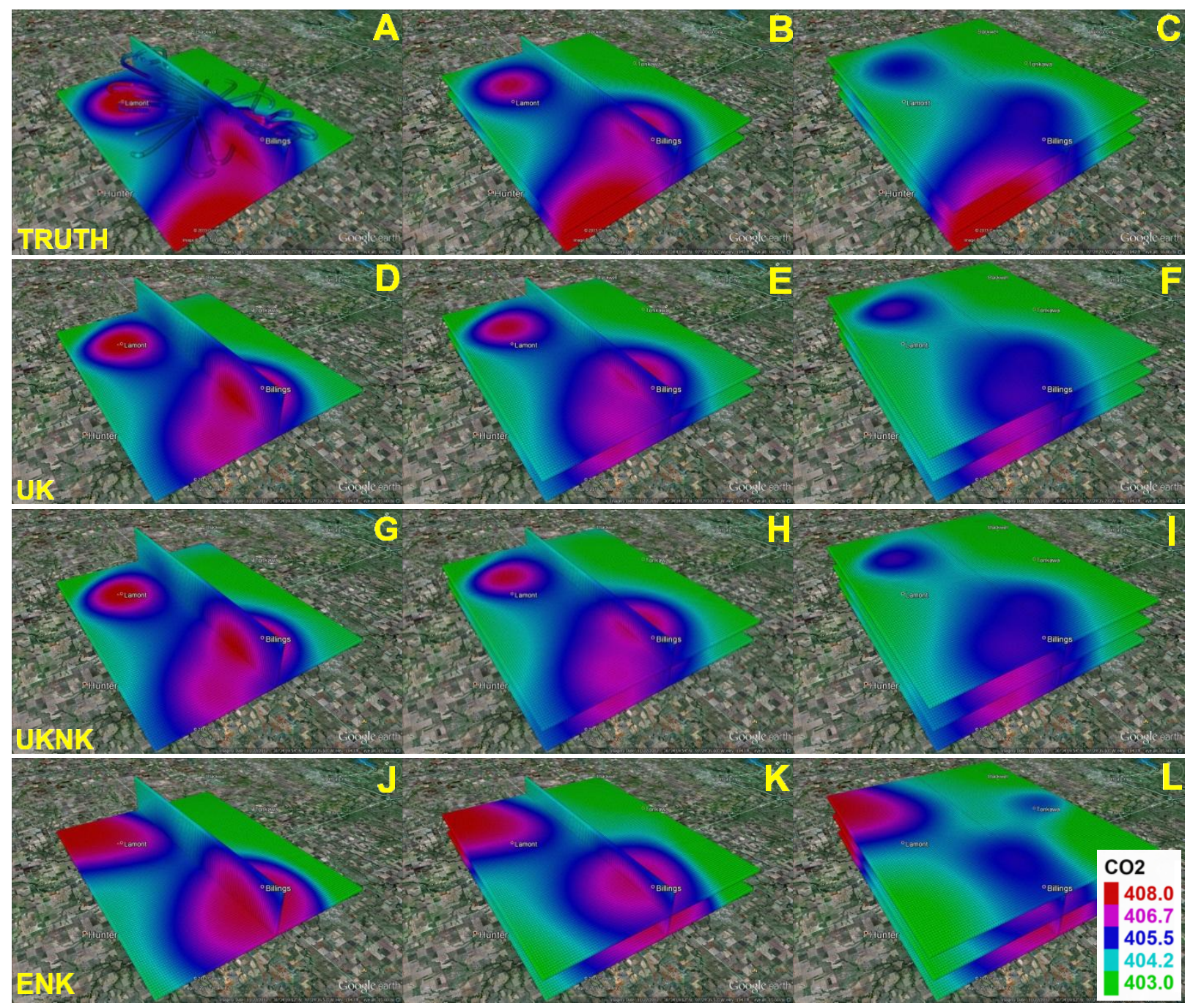

Figure 8. 4S Model. (A-C) Modeled $\mathrm{CO}_{2}$ field. (D-F) Universal kriging estimates using altitude and altitude squared as covariates. (G-I) Universal kriging predictions using ensemble neural network output as covariate, together with altitude and altitude. (J-L) Ensemble neural network predictions. Neither method was able to capture higher mixing ratios at the undersampled far South-West. 